Type of the Paper (Orignal Research.)

\title{
Influence of parents' oral health knowledge and attitudes on oral health practices of children (5-12 years) in a rural school in KwaZulu Natal, South Africa- A cross sectional survey
}

\author{
Prenisha Neupaul ${ }^{1}$, and Ozayr Mahomed ${ }^{2, *}$ \\ 1 Discipline of Public Health Medicine University of KwaZulu Natal 1; e-mail: prenish20@gmail.com \\ 2 Discipline of Public Health Medicine; mahomedo@ukzn.ac.za \\ * Correspondence: mahomedo@ukzn.ac.za; Tel.: (+27 31 2604382)
}

\begin{abstract}
Introduction: Oral health knowledge, beliefs and attitudes of parents have a direct influence on their child's oral health maintenance, dietary habits and encourage healthy behaviors. The aim of this study was to assess the knowledge, and attitude of parents with regards to the oral health practice of their children and its associated factors. Methods: A self -administered structured questionnaire was administered to parents or guardians of learners aged 5 to 12 years at a low socioeconomic rural primary school in the uGu district, KwaZulu Natal, South Africa to collect demographic variables, knowledge of dental health, use of toothbrush, use of toothpaste, dietary practices and dental visits; practice with respect to dental care and attitudes towards oral health. The questionnaire was translated from English to IsiZulu was used. Bivariate and multivariate logistic regressions were used to assess the association between parent's sociodemographic factors with their oral health knowledge and practice scores. Results: One hundred and forty four completed survey instruments were received with an eighty percent (118) representation of mothers. Ninety five percent of the parents (136) had a positive attitude towards oral health with $86 \%$ (124) of the children brushed their tongue and $89 \%$ (128) of the children brushed their teeth happily. The mean knowledge score was $70 \%$ with a median of $72 \%$. Children were significantly more likely to brush their tongues (AOR: 3.20 95\% CI: 1.06-9.66) and were more likely to be happier when brushing their teeth (AOR: 4.65 95\% CI: 1.41-15.38) when the caregivers were their mothers, and when parents had an above average knowledge score (AOR: 1.86 95\% CI: 0.72-4.85) and had positive attitudes (AOR: 3.20 95\%CI: 0.46-22.00). Conclusion: To reduce the gaps in knowledge, oral health promotion should be integrated into all point of care contact with parents at health facilities, increased community awareness and advertising campaigns as well as a more focused school health oral program that addresses primary prevention, screening and appropriate referrals to health facilities.
\end{abstract}

Keywords: knowledge; attitude; practice; children's oral health practice; school going children; rural area 


\section{Introduction}

Oral health diseases are the most common non-communicable disease affecting an estimated half of the world's population [1] with approximately 2.4 billion people suffering from caries of permanent teeth and 486 million children suffering from caries of primary teeth. Untreated cavitated caries in deciduous teeth was the 10th most prevalent condition globally in 2010, affecting 621 million children, with a global population prevalence of $9 \%$ [2]. Although dental caries is prevalent across all countries, the severity was lower in higher income countries versus lower middle-income countries (LMICs).

The prevalence of oral diseases continues to increase in most LMICs, with increasing urbanization and changes in living conditions, inadequate exposure to fluoride and poor access to primary oral health care services. Furthermore, behavioral risk factors for oral diseases such as an unhealthy diet high in free sugars, tobacco use and harmful use of alcohol play a significant role in increasing the risk for oral diseases[3].

In South Africa, there is no reliable epidemiological data at a population level on oral health diseases. The most recent source of oral health data available for children is the National Children's Oral Health Survey (2003)[4]. The findings from the survey indicated that 45- 60 per cent of children who needed treatment for dental caries ranged from and the mean number of teeth needing care per child ranged between 2 to 3 . The needs varied widely from province to province with the greatest need recorded in the Western Cape Province where almost 80 per cent of the children needed care[4]. Applying the Unmet Treatment Need Index (UTN) to the recorded caries rates, the results demonstrated that $80 \%$ of carious lesions in children go untreated[5].

Dental caries often leads to a poor oral health status of a child and is often associated with a negative impact on the quality of life, and the eventual deterioration of health [6]. The consequences of dental caries include pain, decreased appetite, difficulty chewing, difficulty eating some foods, drinking hot or cold beverages, weight loss, difficulty sleeping, changes in behavior and poor academic performance [7]. Children with poor oral hygiene are more likely to miss school when compared to children with good oral hygiene.

Children spend a majority of their time with their parents/guardians[8] more specifically with their mothers and therefore parents play a vital role in instilling good habits and values to their children[8]. The maintenance and outcome of oral health if a young child is highly influenced by parents [9]. Prevention of oral health diseases is more cost effective than treatment and rehabilitation. It is imperative that parents have good oral health knowledge, and attitudes which will influence their child's oral health maintenance, dietary habits and encourage healthy behaviors[9]. Currently, there is a paucity of studies that have been conducted in South Africa that have specifically evaluated knowledge, attitude of parents with regards to the oral health practice of their children. The aim of this study is to assess the knowledge, and attitude of parents with regards to the oral health practice of their children and its associated factors at a low socio-economic rural primary school in the uGu district, KwaZulu Natal, South Africa. 


\section{Subjects and Methods:}

The study setting was a public school situated in a rural location in the Ugu district, Port Shepstone, KwaZulu Natal South Africa. The Primary School is a no-fee school, with 850 learners, caters for children from Grade R to Grade 7. The school provides daily lunch for the children as part of their service. The total number of children from Grade $\mathrm{R}$ to Grade 3 was 468 . The total sample required calculated based on $80 \%$ confidence interval was 120 . The study population included all parents or guardians of learners aged 5 to 12 years (Grade R to Grade 3). We used a self -administered structured questionnaire to collect primary data from participants. The questionnaire and consent forms were designed to be easily read, sealed with in an envelope and was sent along with other school notices via the child's 'homework file'. As an incentive, parents were sent a black ballpoint pen. We followed up with a telephone call to ascertain whether the parents had any questions or uncertainties. The questionnaires were in English and were translated to IsiZulu by an IsiZulu native speaker who is able to speak both English and IsiZulu. Later, it was back-The questionnaire translated to English by another bilingual IsiZulu speaker. Content validity of the questionnaire through a review of the questionnaire by a dentist, teacher and the supervisor.

The questionnaire consisted four sections- Section A- Demographic information such as age, marital status, level of education of both the mother and father and employment status of both parents. Section B- fourteen questions assessed overall knowledge of dental health, use of toothbrush, use of toothpaste, dietary practices and dental visits. The questions consisted of a combination of binary options (yes and no), multiple choice questions and rating questions using agree', 'disagree' and 'don't know' on a modified Likert scale. Section C- three questions tested practice with respect to dental care. Section D- a single question assessed attitudes towards oral health.

The Biomedical Research Ethics Committee of the University of KwaZulu-Natal (Reference number BE677/17) provided ethical approval and authorization was obtained from the Department of Education. All parents signed informed consent prior to completing the questionnaire.

The data was entered into Microsoft Excel 2013 spreadsheets and exported to StataCorp. 2013. Stata Statistical Software: Release 13.

An initial descriptive analysis of baseline characteristics such as age, education, knowledge and of oral health practices of participants was performed. The average and median scores for Knowledge and practice were calculated by allocating a single point to all correct answers. The scores were then categorized as good or below par score. Bivariate and multivariate logistic regressions were used to assess the association between parent's sociodemographic factors with their oral health knowledge and practice scores.

\section{Results}




\subsection{Sociodemographic Profile of the parents}

One hundred and forty four completed survey instruments were received. Eighty percent (118) of the participants completing the survey were mothers of the children. Seventy nine percent of the parents (115) were below the age of forty. Eighty three percent (120) of the parents were single. One hundred and twenty five $(87 \%)$ of the parents classified their area of residence as rural. The majority of parents (both mothers (64\%) and fathers (65\%)) had a high school education and above. The majority of the mothers $(60 \%)$ were unemployed (Table 1$)$.

Table 1: Sociodemographic Profile of parents of students

\begin{tabular}{|c|c|c|}
\hline Relationship to child & $\mathbf{N}$ & $\%$ \\
\hline Mother & 118 & $82 \%$ \\
\hline Father & 8 & $6 \%$ \\
\hline Grandmother & 13 & $9 \%$ \\
\hline Grandfather & 2 & $1 \%$ \\
\hline Other guardian. & 3 & $2 \%$ \\
\hline Age & $\mathbf{N}$ & $\%$ \\
\hline 18 to 29 years & 48 & $33 \%$ \\
\hline 30 to 39 years & 66 & $46 \%$ \\
\hline 40 to 59 years & 28 & $19 \%$ \\
\hline$>60$ years & 2 & $1 \%$ \\
\hline Marital status & $\mathbf{N}$ & $\%$ \\
\hline Single & 120 & $83 \%$ \\
\hline Married & 13 & $9 \%$ \\
\hline Divorced & 11 & $8 \%$ \\
\hline Mothers Education Status & $\mathbf{N}$ & $\%$ \\
\hline Primary school and lower & 52 & $36 \%$ \\
\hline High school and above & 92 & $64 \%$ \\
\hline Father education level & $\mathbf{N}$ & $\%$ \\
\hline Primary school and lower & 65 & $45 \%$ \\
\hline High school and above & 79 & $65 \%$ \\
\hline Mother Employment & $\mathbf{N}$ & $\%$ \\
\hline Unemployed & 86 & $60 \%$ \\
\hline Employed & 58 & $40 \%$ \\
\hline Fathers Employment & $\mathbf{N}$ & $\%$ \\
\hline Unemployed & 48 & $33 \%$ \\
\hline Employed & 96 & $66 \%$ \\
\hline Residence & $\mathbf{N}$ & $\%$ \\
\hline Rural area & 125 & $87 \%$ \\
\hline Urban area & 19 & $13 \%$ \\
\hline
\end{tabular}

3.2. Attitude of parents towards dental health 
Ninety five percent of the parents (136) had a positive attitude towards oral health by rating oral health as very important or important in relation to other health conditions in general (Table 2).

Table 2: Frequency table of parent's attitude towards Oral Health

\begin{tabular}{|l|r|r|}
\hline Variable & Frequency (n) & Percentage (\%) \\
\hline Attitude towards dental health & 100 & $69,4 \%$ \\
\hline Very important & 36 & $25 \%$ \\
\hline Important & 5 & $3,5 \%$ \\
\hline Neutral & 2 & $1,4 \%$ \\
\hline Less important & 1 & $0,7 \%$ \\
\hline Not important & &
\end{tabular}

\subsection{Children's oral health practices}

Parents reported that $86 \%$ (124) of the children brushed their tongue and $89 \%$ (128) of the children brushed their teeth happily (Table 3).

Table 3: Frequency table of children's Oral Health Practices

\begin{tabular}{|c|c|c|}
\hline Variable & Frequency (n) & Percentage $(\%)$ \\
\hline \multicolumn{3}{|c|}{ Children's Practice } \\
\hline \multicolumn{3}{|c|}{ Brushing of tongue } \\
\hline Yes & 124 & $86,1 \%$ \\
\hline No & 19 & $13,2 \%$ \\
\hline Don't know & 1 & $0,7 \%$ \\
\hline \multicolumn{3}{|c|}{ Childs mood when brushing teeth } \\
\hline Happily & 128 & $89 \%$ \\
\hline Sad & 4 & $3 \%$ \\
\hline Resistant & 12 & $8 \%$ \\
\hline
\end{tabular}

\subsection{Parental knowledge of oral health practices}

The majority of parents correctly answered the knowledge questions. The mean knowledge score was $70 \%(9.75 / 14)$ with a median of $72 \%(10 / 14)$. Less than $70 \%$ of the parents correctly answered the following questions: the best time for sweets and cool drinks (40\% incorrect); period in which a toothbrush needs to be changed ( $38 \%$ incorrect); best bushing methods for a child ( $46 \%$ incorrect); amount of toothpaste (51\% incorrect); first course of action to take place when a child complains of toothache (49\% incorrect) ; long term breastfeeding ( $55 \%$ incorrect); transmission of germs between mother and child if same teaspoon was used ( $38 \%$ incorrect) (Table 4 ). 
Parental knowledge

Age in which the child's first tooth grew.

$\mathbf{N}$

6-10 months

10-16 months

Don't know

Best time to give your child sweets and cool drinks such as Coke.

After meals

In-between meals

At night, before bed

Don't know

Foods that cause teeth to rot in children.

Chocolate

Biscuits

Fruits

Cakes

Period in which a toothbrush should be changed.

Every 3 months

Every 6 months

When the bristles start to splay

Don't know

Frequency of tooth brushing.

Twice a day

Once a day

After every meal

Best brushing method for a child.

Circular motions

Scrubbing to and fro

Doesn't matter

\begin{tabular}{|c|c|}
\hline 113 & $78,5 \%$ \\
\hline 13 & $9 \%$ \\
\hline 18 & $12,5 \%$ \\
\hline
\end{tabular}

The use of fluoride toothpaste prevents holes in teeth (tooth decay).

\begin{tabular}{|l|c|c|}
\hline Agree & 102 & $70,8 \%$ \\
\hline Disagree & 13 & $9 \%$ \\
\hline Don't know & 29 & $20,1 \%$ \\
\hline First course of action when your child has a toothache. & 47 & $32,6 \%$ \\
\hline Give a pain killer & 20 & $13,9 \%$ \\
\hline Gargle with salt water & 1 & $0,7 \%$ \\
\hline Ask child to eat on the opposite side & 74 & $51,4 \%$ \\
\hline Take child to local clinic or dentist & 2 & $1,4 \%$ \\
\hline Don't know & & \\
\hline Amount of toothpaste placed on a brush. & & \\
\hline
\end{tabular}




\begin{tabular}{|l|r|r|}
\hline Small pea-size & 70 & $48,6 \%$ \\
\hline Full-length & 57 & $39,6 \%$ \\
\hline Doesn't matter & 17 & $11,8 \%$ \\
\hline
\end{tabular}

With the growth of the first baby teeth, parents can begin to clean them with a piece of gauze or a clean washcloth.

\begin{tabular}{|c|c|c|}
\hline Agree & 96 & $66,7 \%$ \\
\hline Disagree & 20 & $13,9 \%$ \\
\hline Don't know & 28 & $19,4 \%$ \\
\hline \multicolumn{3}{|c|}{ Breast-feeding for a long time causes holes in teeth (decay). } \\
\hline Agree & 56 & $38,9 \%$ \\
\hline Disagree & 63 & $43,8 \%$ \\
\hline Don't know & 25 & $17,4 \%$ \\
\hline \multicolumn{3}{|c|}{ Eating too much of food containing sugar can cause holes in teeth (cavities). } \\
\hline Agree & 128 & $88,9 \%$ \\
\hline Disagree & 3 & $2,1 \%$ \\
\hline Don't know & 13 & $9 \%$ \\
\hline \multicolumn{3}{|c|}{ If a baby sleeps with a milk bottle all night this will result in holes in teeth (tooth decay). } \\
\hline Agree & 94 & $65,3 \%$ \\
\hline Disagree & 10 & $6,9 \%$ \\
\hline Don't know & 40 & $27,8 \%$ \\
\hline \multicolumn{3}{|c|}{$\begin{array}{l}\text { Bacteria (germs) from the mother's mouth can be passed to her child if she uses the same spoon when } \\
\text { feeding her baby. }\end{array}$} \\
\hline Agree & 87 & $60,4 \%$ \\
\hline Disagree & 27 & $18,8 \%$ \\
\hline Don't know & 30 & $20,8 \%$ \\
\hline
\end{tabular}


3.4. Bivariate and multivariate association between socio-demographic factors and parent's knowledge, attutudes and childrens oral health practices

After bivariate analysis mothers (UOR: 1.49 95\% CI: 0.58-4.00) and parents between 18 and 29 years of age (UOR: 1.16 95\% CI: 0.55-2.45) showed an increased odds of better oral health knowledge. After multivariate analysis, mothers showed an increased but non-significant odds (AOR: 1.43 95\%CI: 0.58-3.42) of better oral health knowledge compared to fathers, grandparents and other caregivers.

Mothers (AOR: 4.17 95\% CI: 0.60-26.80); high school education and above (AOR: 1.36 95\%CI: 0.228.59); parents from urban areas (AOR: 1.98 95\% CI: 0.18-21.47) and parents with above average knowledge scores (AOR: 4.48 95\% CI: 0.50-40.20) had a non-significant increased odds of a better attitude towards oral health.

Children were significantly more likely to brush their tongues (AOR: 3.20 95\% CI: 1.06-9.66) and were more likely to be happier when brushing their teeth (AOR: 4.65 95\% CI: 1.41-15.38) when the caregivers were their mothers. Furthermore, children were more likely to be happier brushing their teeth when parents had an above average knowledge score (AOR: 1.86 95\% CI: 0.72-4.85) and had positive attitudes (AOR: 3.20 95\%CI: 0.46-22.00). In addition, children were more likely to brush their tongues (AOR: 2.70 95\% CI: 0.40-19.21) when parents had positive attitudes towards oral health (Table 5). 
Table 5: Bivariate and multivariate analysis of socio-demographic factors versus knowledge, attitude and children's oral health practices

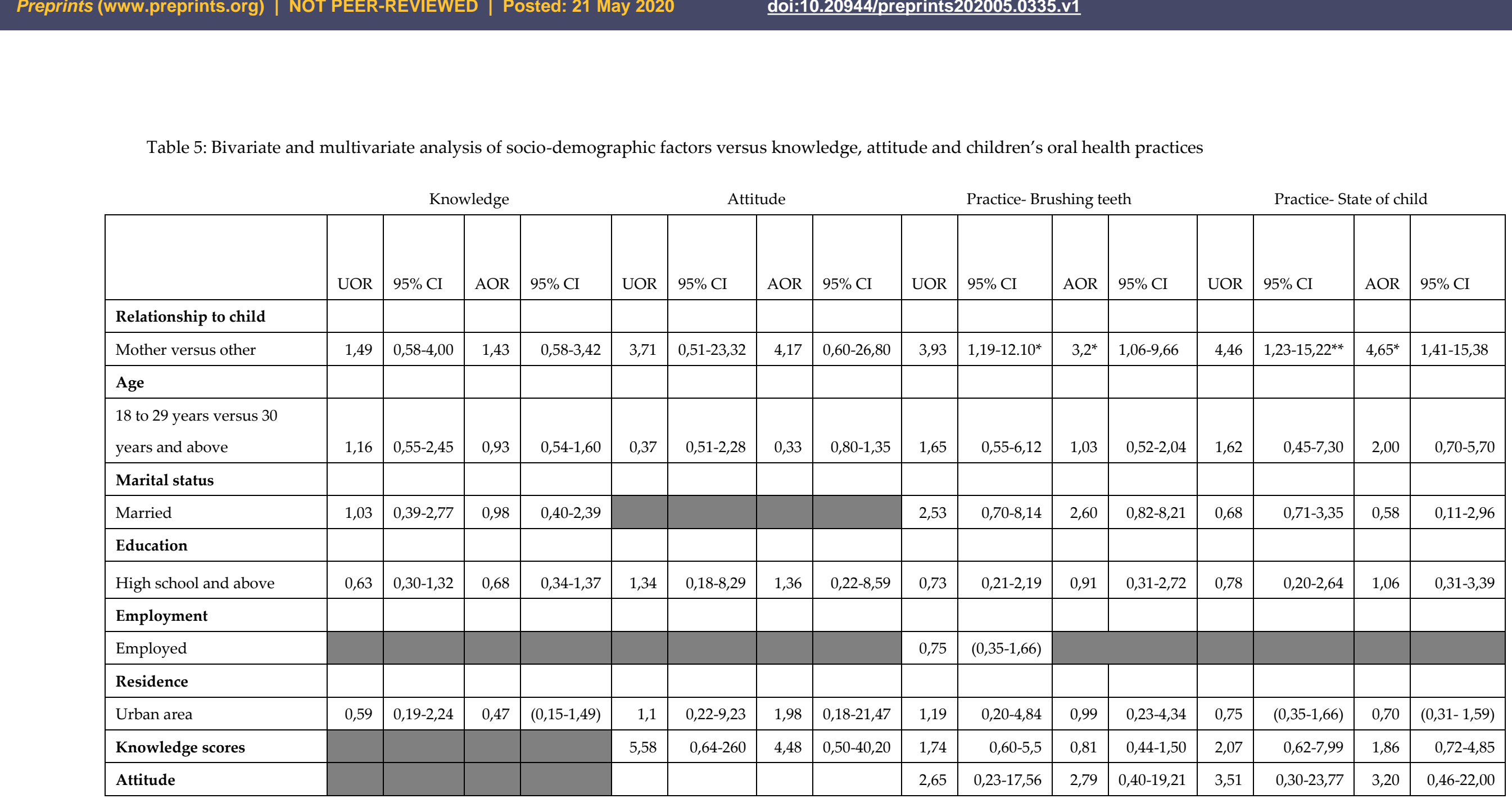




\section{Discussion}

According to our experience, this study is amongst the first that have been conducted amongst parents of school going children in a rural area of South Africa. The demographic profile of the participants - less than 40 years of age, majority being single parents, unemployed and a high school education and above are generally representative of a lower socio-economic community in South Africa. The above demographic profile of participants share similarities with studies conducted in Nepal[10] and Belagavi, Karnataka[11].

Despite, the wide confidence interval due to a small sample size, the most significant findings of the study was that when the when the caregivers were their mothers children were significantly more likely to brush their tongues (AOR: $3.2095 \%$ CI: 1.06-9.66) and were more likely to be happier when brushing their teeth (AOR: 4.65 95\% CI: 1.41-15.38). Mothers are often the main role model to their children and usually have more knowledge compared to fathers regarding their child's oral health[12]. A number of previous studies have indicated that the mother's support is significantly associated with the tooth brushing habits of children aged 1-3 years but not with those of children aged 4-5 years [15]. For older age children, the child's gender, the mother and father's education, and the caregiver's tooth brushing frequency and oral health knowledge were more likely to influence the tooth brushing habits of older children [13]. This is further corroborated by the current study that indicates when parents had an above average knowledge score (AOR: 1.86 95\% CI: 0.724.85 ) and when parents positive attitudes towards oral health (AOR: $3.2095 \%$ CI: 0.46-22.00), the children were happier when brushing their teeth.

Younger parents between 18 and 29 years of age showed a slightly increased likelihood of better oral health knowledge, with an increased likelihood of the children brushing their gums and having a positive frame of mind towards brushing their teeth. However, there was no significant correlation between mother's age with either dental health knowledge or practices. Similar findings were noted in a survey conducted in district hospitals of Srinagar, Kashmir amongst women with children below 12 years of age[14] and a further study conducted in Nigeria[15]. Younger parents generally have better computer, internet and smart phone literacy and would therefore have greater access to oral health-related knowledge[16].

The findings of our current study indicate areas of strength and weakness in the knowledge of participating parents. The majority of parents were aware of the role in which diet plays on oral health, the role of excessive intake of food containing sugar could cause cavities in teeth,. Similar findings were noted in a at vaccination centers from six geographic districts in Kuwait[16]. Good parental knowledge on dietary factors affecting children's oral health were also demonstrated in a cross sectional study conducted amongst mothers of the children aged between 1 and 4 years, attending the pediatric division of government district hospitals in Moradabad, India that showed $73 \%$ of mothers had good knowledge of diet and dietary practices[9]. The increased knowledge on the role of sugar containing foods on the child's oral health status could be attributed to the health promotion messages provided about sugar intake.

Parents in our study were knowledgeable on the role of fluoride toothpaste in preventing dental caries, the correct amount of toothpaste, twice daily brushing of teeth and the correct brushing technique required. These findings were similar to the previously quoted Indian study[17]. A possible reason for the high knowledge amongst parents in our study is possibly due to the diffusion of the knowledge from the children to the parents. The school in the current study is included in the district oral health school team program which includes an oral hygienist who provides oral health education to children on the correct use of a toothbrush and tooth paste as well as provides toothbrushes and tooth paste to the students. 
The majority of parents had knowledge regarding the transmission of bacteria when sharing utensils. These findings were slightly lower but similar to the study in Rajnandgaon, India[17], however contradictory findings of lower knowledge on transmissibility by sharing utensils and toys were noted in studies in Nigeria[18], India[9] and Brazil[19].

A population based cohort study in Brazil indicated that breastfeeding for more than 24 months is associated with an increased risk of dental caries [20]. The finding of a high proportion of parents unaware of the risk of prolonged breast feeding is not unique to our study as similar findings were noted from a study conducted amongst mothers of 3-6-year-old primary school children from public primary schools of the city, in Rajnandgaonin, India where $65 \%$ of mothers were not aware or did not know that prolonged breastfeeding resulted in tooth decay[17] and a study amongst 200 rural mothers from nearby villages and 200 urban mothers from Udaipur city that showed $47 \%$ of mothers were unaware that frequent and prolonged breast feeding was associated with dental caries[21].

A majority of parents (75.7\%) in the present study believed that long term bottle feeding is a causative factor of tooth decay and $63,5 \%(n=93)$ agreed that leaving the milk bottle at night in the child's mouth increases their risk of tooth decay. The knowledge of prolonged nocturnal bottle feeding in our study is lower than the findings from the previous quoted study in Rajnandgaonin, India that $80 \%$ of parents were aware of the harmful effect of prolonged nocturnal bottle feeding[17]. This is in contrast to findings from paediatric clinics (well-baby clinics) of Security Forces Hospital in Makkah Al-Mukarrama that showed more than half of the mothers (54.5\%) agreed that letting baby sleep with bottle still in the mouth was of no harm to teeth[22]. Similar low levels of knowledge on the role of nocturnal bottle feeding was noted in a study in Addis Ababa, Ethiopia that showed only $25 \%$ of mothers were aware that nocturnal bottle feeding may increase risk of dental caries[23]. The relatively better knowledge in our study participants could be attributed to the promotion of exclusive breastfeeding at clinics during antenatal care, the provision of information on bottle hygiene and the risks associated with prolonged bottle feeding.

\section{Limitations}

Although due diligence was maintained to ensure the integrity of the study, the findings of the study are influenced by limited sample size. Only parents who signed the consent forms were included in the study sample. Hence the results, even though they may give insight to the current situation, may not be generalized to the whole Grade R to Grade 3 population of parents and children in the Ugu District of KwaZulu-Natal in 2018.

\section{Conclusions}

Parents in the rural community have a positive attitude towards and children display good practices. Overall parents have satisfactory knowledge on oral health, with a number of areas of gaps in knowledge. To reduce the gaps in knowledge, oral health promotion should be integrated into all point of care contact with parents at health facilities, increased community awareness and advertising campaigns as well as a more focused school health oral program that addresses primary prevention, screening and appropriate referrals to health facilities.

Author Contributions: P.N: “Conceptualization, data collection; initial analysis and writing-original draft preparation. OM: advise on methodology; formal analysis, writing-review and editing, and supervision. Funding: "This research received no external funding"

\section{Acknowledgments: Nil}

Conflicts of Interest: “The authors declare no conflict of interest." 


\section{References}

1. 1. Global Burden of Disease Cancer, C.; Fitzmaurice, C.; Akinyemiju, T.F.; Al Lami, F.H.; Alam, T.; Alizadeh-Navaei, R.; Allen, C.; Alsharif, U.; Alvis-Guzman, N.; Amini, E., et al. Global, Regional, and National Cancer Incidence, Mortality, Years of Life Lost, Years Lived With Disability, and DisabilityAdjusted Life-Years for 29 Cancer Groups, 1990 to 2016: A Systematic Analysis for the Global Burden of Disease Study. JAMA Oncol 2018, 10.1001/jamaoncol.2018.2706, doi:10.1001/jamaoncol.2018.2706.

2. 2. Kassebaum, N.J.; Bernabe, E.; Dahiya, M.; Bhandari, B.; Murray, C.J.; Marcenes, W. Global burden of untreated caries: a systematic review and metaregression. J Dent Res 2015, 94, 650-658, doi:10.1177/0022034515573272.

3. 3. World Health Organisation. Oral Health. Availabe online: https://www.who.int/news-room/factsheets/detail/oral-health (accessed on 9 July).

4. 4. National Department of Health. National Children's Oral Health Survey National Department of Health: Pretoria, 2003; pp 1-18.

5. 5. van Wyk, P.J.; van Wyk, C. Oral health in South Africa. Int Dent J 2004, 54, 373-377.

6. 6. Scarpelli, A.C.; Paiva, S.M.; Viegas, C.M.; Carvalho, A.C.; Ferreira, F.M.; Pordeus, I.A. Oral healthrelated quality of life among Brazilian preschool children. Community Dent Oral Epidemiol 2013, 41, 336-344, doi:10.1111/cdoe.12022.

7. 7. Ramos-Jorge, J.; Pordeus, I.A.; Ramos-Jorge, M.L.; Marques, L.S.; Paiva, S.M. Impact of untreated dental caries on quality of life of preschool children: different stages and activity. Community Dent Oral Epidemiol 2014, 42, 311-322, doi:10.1111/cdoe.12086.

8. 8. Sultan, S.; Ain, T.S.; Gowhar, O. Awareness of Mothers Regarding Oral Health of their Children in Kashmir, India. International Journal of Contemporary Medical Research 2016, 3, 2168-2171.

9. 9. Suresh, B.S.; Ravishankar, T.L.; Chaitra, T.R.; Mohapatra, A.K.; Gupta, V. Mother's knowledge about pre-school child's oral health. J Indian Soc Pedod Prev Dent 2010, 28, 282-287, doi:10.4103/0970-4388.76159.

10. 10. Khanduri, N.; Singhal, N.; Mitra, M.; Rohatgi, S. Knowledge, attitude, and practices of parents toward their children's oral health: A questionnaire survey in Bhairahawa (Nepal). Int J Pedod Rehabil 2018, 3, 5961.

11. 11. Suma Sogi, H.P.; Hugar, S.M.; Nalawade, T.M.; Sinha, A.; Hugar, S.; Mallikarjuna, R.M. Knowledge, attitude, and practices of oral health care in prevention of early childhood caries among parents of children in Belagavi city: A Questionnaire study. J Family Med Prim Care 2016, 5, 286-290, doi:10.4103/22494863.192332.

12. 12. Nagarajappa, R.; Kakatkar, G.; Sharda, A.J.; Asawa, K.; Ramesh, G.; Sandesh, N. Infant oral health: Knowledge, attitude and practices of parents in Udaipur, India. Dent Res J (Isfahan) 2013, 10, 659-665.

13. 13. Qiu, R.M.; Tao, Y.; Zhou, Y.; Zhi, Q.H.; Lin, H.C. The relationship between children's oral healthrelated behaviors and their caregiver's social support. BMC Oral Health 2016, 16, 86, doi:10.1186/s12903-0160270-4.

14. 14. Sultan, S.; Ain, T.; Gowhar, O. Awareness of Mothers Regarding Oral Health of their Children in Kashmir, India. International Journal of Contemporary Medical Research 2016, 3, 2168-2172.

15. 15. Abiola Adeniyi, A.; Eyitope Ogunbodede, O.; Sonny Jeboda, O.; Morenike Folayan, O. Do maternal factors influence the dental health status of Nigerian pre-school children? Int J Paediatr Dent 2009, 19, 448454, doi:10.1111/j.1365-263X.2009.01019.x.

16. 16. Ashkanani, F.; Al-Sane, M. Knowledge, attitudes and practices of caregivers in relation to oral health of preschool children. Med Princ Pract 2013, 22, 167-172, doi:10.1159/000341764.

17. 17. Shetty, R.M.; Deoghare, A.; Rath, S.; Sarda, R.; Tamrakar, A. Influence of mother's oral health care knowledge on oral health status of their preschool child. Saudi J Oral Sci 2016, 3, 6.

18. 18. Abduljalil, H.S.; Abuaffan, A.H. Knowledge and Practice of Mothers in Relation to Dental Health of PreSchool Children. Advancements in Genetic Engineering 2016, 5, doi:10.4172/2169-0111.1000153.

19. 19. Sakai, V.T.; Oliveira, T.M.; Silva, T.C.; Moretti, A.B.; Geller-Palti, D.; Biella, V.A.; Machado, M.A. Knowledge and attitude of parents or caretakers regarding transmissibility of caries disease. J Appl Oral Sci 2008, 16, 150-154, doi:10.1590/s1678-77572008000200013.

20. 20. Peres, K.G.; Nascimento, G.G.; Peres, M.A.; Mittinty, M.N.; Demarco, F.F.; Santos, I.S.; Matijasevich, A.; Barros, A.J.D. Impact of Prolonged Breastfeeding on Dental Caries: A Population-Based Birth Cohort Study. Pediatrics 2017, 140, doi:10.1542/peds.2016-2943. 
21. 21. Dogra, S.; Arora, R.; Bhayya, D.P.; Thakur, D. Knowledge and Attitude of Lactating Mothers towards Infant oral health care in Udaipur. OSR Journal of Dental and Medical Sciences (IOSR-JDMS) 2014, 13, 57-60.

22. 22. Al-Zahrani, A.; Al-Mushayt, A.; Otaibi, M.F.; Wyne, A. Knowledge and attitude of Saudi mothers towards their preschool children's oral health. Pak J Med Sci 2014, 30 720-724, doi:http://dx.doi.org/10.12669/pjms.304.5069.

23. 23. Duguma, F.K.; Zemed, B. Assessment of Knowledge, Attitude and Practice (KAP) of Parents Towards Childhood Dental Caries Attending Pediatrics and Dental Clinic at ALERT Center, Addis Ababa, Ethiopia, January 2018. Adv Dent E Oral Health 2019, 11, doi:10.19080/ADOH.2019.11.555806. 